\title{
Pubo-Penile Ectopic Testis: A Rare Entity
}

\author{
Gaurav Gupta ${ }^{1}$, Prateek Sharda ${ }^{1 *}$, Sangeeta Gupta ${ }^{2}$, Sonam Agrawal ${ }^{3}$, Prabhjyot bir singh ${ }^{4}$ and Sameer Singla ${ }^{4}$ \\ ${ }^{1}$ Department of Surgery, Maharishi Markandeshwar Medical college \& Research, India
}

${ }^{2}$ Department of Physiology, Maharishi Markandeshwar Medical college \& Research, India

${ }^{3}$ Department of Pediatrics, Maharishi Markandeshwar Medical college \& Research, India

${ }^{4}$ Postgraduate student in general surgery, Maharishi Markandeshwar Medical college \& Research, India

Submission: March 30, 2017; Published: April 04, 2017

*Corresponding author: Prateek Sharda, Senior Resident (MBBS, MS), Department of Surgery, Maharishi Markandeshwar Medical college \& Research, Mullana, Ambala, Haryana, India; Tel: +919992599916; Email: prateeksharda2006@gmail.com

\section{Abstract}

An ectopic testis is one which has deviated from its usual path of descent. Pubo-Penile ectopic testis is a rare congenital anomaly in which the testis is abnormally situated along the penile shaft or around its root. In this case, the condition was present since birth but presented to hospital during adolescence \& was successfully treated.

Keywords: Pubo-Penile ectopic testis; Gubernaculum

\section{Introduction}

Ectopic testis is one which has deviated from its usual path of descent and is not found in regions of usual descent into the scrotum. Testicular maldescent or cryptorchidism is the most common anomaly of the genitalia with an incidence of approximately $1 \%$ in male newborns. It is commoner on the right side, and in premature neonates [1,2]. It is reported that $5 \%$ of maldescended testes are ectopic [3] Ectopic testis (Testicular ectopia) specifically describes inguinoscrotal descent outside the normal boundaries. The major sites of ectopic testes are the superficial inguinal pouch, femoral, suprapubic, penile, transverse (contralateral hemiscrotum), and perineal. Penile ectopic testis is a rare congenital anomaly in which the testis is abnormally situated along the penile shaft or around its root. These conditions present at birth or within two years of childhood, definitive treatment of this condition is thus usually done in childhood. In this case, the condition was present at birth but presented to hospital during adolescence.

\section{Case Report}

Thirteen year old male child presented with a history of swelling at the base of penis and absence of left testis in the scrotum. The condition had been present since birth. Social reasons hampered earlier referral for appropriate medical care. There had been progressive penile development, in association with a swelling, and normal secondary sexual characteristics. His general and systemic examination was normal. On local examination right testis was normally placed in the scrotum and it was normal in size and shape. Left side of the scrotum was empty with hypoplastic scrotal sac and normally developed external genetalia. There was a single, well defined, mobile, oval shaped swelling of size $3 \times 2 \times 2 \mathrm{~cm}$, palpable at the base of the penis (Figure 1).

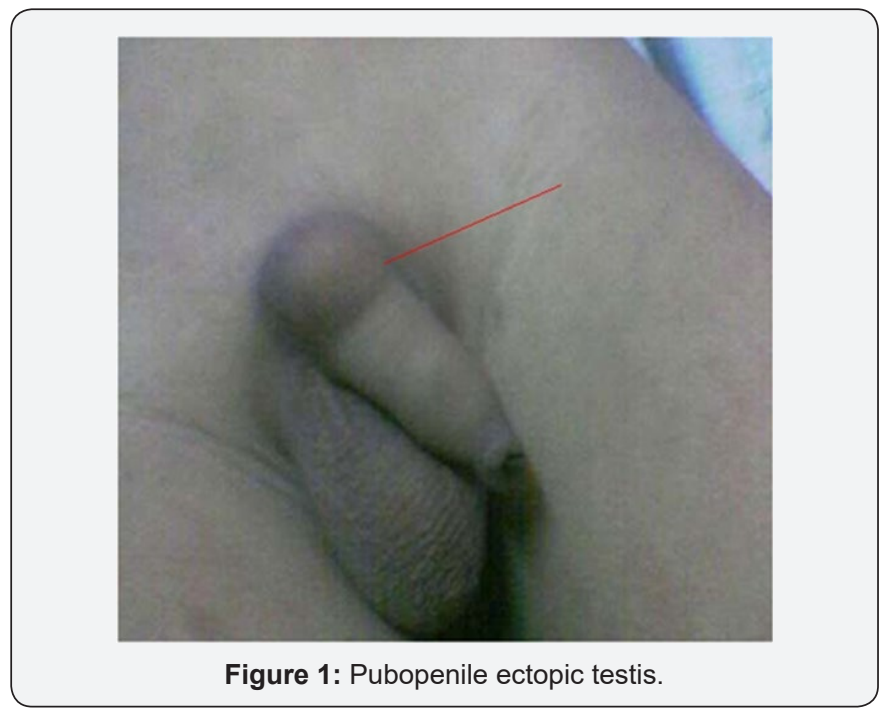


Skin over the swelling was free and overlying skin color was normal. Testicular sensations were preserved on right side while on compression of the palpable mass there was sickening sensation that was felt in peri-umbilical area, a sign in favor of ectopic testis. His ultrasound abdomen was normal $\&$ it confirmed the ectopic location of the testis. Left inguinal region was explored under spinal anesthesia. There was a well developed testis which was present over the pubic tubercle and was attached to the spermatic cord. Orchidopexy was done $\&$ testis was anchored in the left extra dartos pouch (Figure 2). Child made uneventful recovery, and was doing well on subsequent follow up (Figure 2).

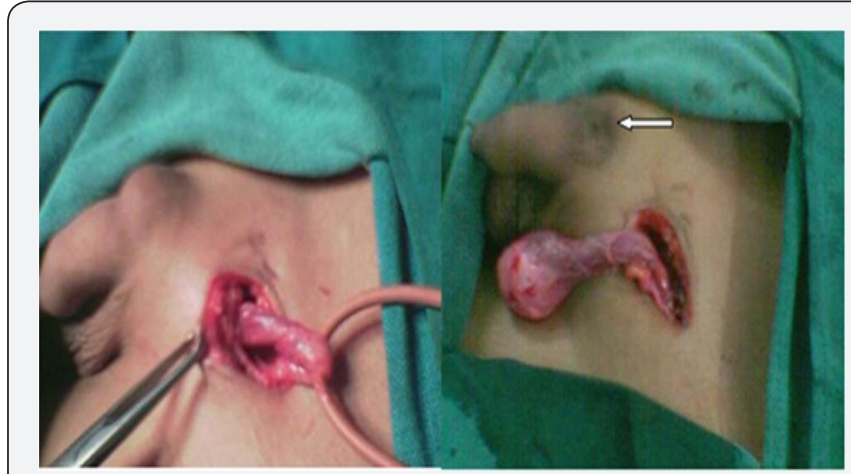

Figure 2: Ectopic testis before orchidopexy.

\section{Discussion}

An ectopic testis is one which has deviated from its usual path of descent. In both ectopic and undescended testis the scrotum of the same side will be empty. If the swelling is within the inguinal canal it is probably an undescended testis. A testis is recognized by its shape, size, feel and testicular sensation. The undescended testis is smaller and less developed than its fellow in the scrotum [3-5] but an ectopic testis is always well developed. Though the commonest position of ectopic testis is at the superficial inguinal pouch, yet ectopic testis may be found at the root of penis (Pubic type), at the perineum (Perineal type), at the upper and at the medial part of the femoral triangle (Femoral type). Site of the ectopic testis is probably decided by the strength of the tail of gubernaculum. Normally scrotal tail is the strongest hence testis descends down into the scrotum [6,7]. In the case under review, Ultrasound scan confirmed the swelling to be a testis in the ectopic location. There was no relevance of computerized tomography, which is however useful for cryptorchidism with an intra-abdominal location of the testis [8]. The gubernacular tail theory provides a simple and valid explanation for the etiology of penile ectopic testis $[9,10]$. The presence of a gubernaculum attached to the penile fascia of Buck indicates an anomalous growth and termination of its extra-abdominal portion.

To detect these anomalies in early childhood is important; however the condition is correctible even at the later stages. Possible intervention by Health policy custodians, like the Ministry of Health, can be geared at notification of urogenitalinguinal anomalies at birth and at times of child health visits to health facilities. This can go hand in hand with ano-rectal malformation notification. Anorectal anomalies are reported early more frequently because of their intestinal obstructive effect. Testicular maldescent, occurring in every 1 in 100 births, deserves a place in the child health card. It was concluded that a penile ectopic testis, normal in size, may present during adolescence. The condition is correctible though there is need for screening and early detection in children through National Health Policy interventions.

\section{References}

1. Sadler TW (2004) Langman's Medical Embryology. $9^{\text {th }}$ edition. Lippincott, Williams and Wilkins. Baltimore ch 14: 357-359.

2. Levin A, Sherman J0 (1973) The undescended testis. Surg Gynaecol Obstet 136(3): 473-479.

3. Hegde DK, Lal SS, Shilotri PP, Patkar AN (1987) Penile ectopic testis. Indian J Urol 3(2): 85-86

4. Albin R, Reyes HM, Replogle RC (1972) A penile testis. J Pediatr Surg 7(3): 308-309.

5. Concodora JA, Evans RA, Smith MJ (1976) Ectopic penile testis. Urology 8(3): 263-264.

6. Alonso Domínguez F, Osorio Acosta V (2004) A rare case of testicular ectopia. Arch Esp Urol 57(5): 547-549.

7. Nounla J, Tröbs RB, Rolle U (2001) Perineal Ectopic Testis: A Rare Cause of Empty Scrotum. Urol Int 67(3): 246-248.

8. Nouira F, Ben Ahmed Y, Jlidi S, Chariag A, Ghorbel S, et al. (2011) Management of perineal ectopic testes. La Tunisie Medicalel 89(1): 47-49.

9. Gaur DD, Purohit KC, Joshi AS, Mehta V, Madhusudhana HR (1999) Subumbilical ectopic testis. BJU Int 84(7): 887.

10. Rao PL, Gupta V, Kumar V (2005) Anterior abdominal wall: an unusual site for ectopic testis. Pediatr Surg Int 21(8): 687-688. 


\section{Your next submission with Juniper Publishers} will reach you the below assets

- Quality Editorial service

- Swift Peer Review

- Reprints availability

- E-prints Service

- Manuscript Podcast for convenient understanding

- Global attainment for your research

- Manuscript accessibility in different formats ( Pdf, E-pub, Full Text, Audio)

- Unceasing customer service

Track the below URL for one-step submission https://juniperpublishers.com/online-submission.php 